\title{
A COMPARATIVE STUDY OF CELLULOSE NANOWHISKERS (CNWs) AND CELLULOSE NANOFIBERS (CNFs)
}

\author{
ZHIJUN HU, XINYU CAO, DALIANG GUO, YINCHAO XU, PING WU, \\ PETER CHRISTIE and JING LI \\ Zhejiang University of Science and Technology, 318 Liuhe Road, Xihu District, \\ Hangzhou 310023, China \\ $\bowtie$ Corresponding author: Zhijun Hu, foxhuz@163.com
}

Received May 20, 2020

\begin{abstract}
Cellulose nanowhiskers (CNWs) from plant biomass are of considerable interest, primarily due to their low density, biodegradability, mechanical strength, economic output, and renewability. Here, a new pretreatment method has been developed to produce $\mathrm{CNW}$ s based on supercritical $\mathrm{CO}_{2}$ and ethanol. The raw material was micro-fibrillated cellulose (MFC) and experimental factors were controlled to enhance the properties of CNWs produced using a ball-milling technique following supercritical $\mathrm{CO}_{2}$ pretreatment. Cellulose nanofibers (CNFs) were also prepared using a highpressure Microfluidizer $($. A comparative study was conducted of the properties of the raw materials, the CNWs and the CNFs. The solid yields of P-MFC after supercritical $\mathrm{CO}_{2}$ pretreatment gradually decreased, along with the temperature and the reaction time. Scanning electron microscopy (SEM) images of the CNWs and CNFs show that the morphology of the CNWs was basically acicular, while that of the CNFs was mainly soft fibrous. Thermogravimetric analysis results suggest that the thermal stability of the CNWs was substantially higher than those of the CNFs and the raw material. XRD results indicate that the crystallinity showed an initial increasing trend and then declined with increasing temperature and reaction time, and the crystallinity value of CNWs was higher than that of CNFs. The smaller CNWs became rougher and had a larger surface area.
\end{abstract}

Keywords: ball-milling, cellulose nanowhiskers, ethanol, supercritical carbon dioxide

\section{INTRODUCTION}

In recent years, increasing attention has been paid to nanocellulose, ${ }^{1}$ and there are many efficient methods to extract nanocellulose from different lignocellulosic materials. ${ }^{2-4}$ Cellulose nanowhiskers (CNWs) have become recognized globally as a natural material, with great potential in the development of new green nanocomposites, which can be obtained from abundant renewable resources. ${ }^{5}$ CNWs have applications in the engineering field, including electronic and optical equipment, ${ }^{6}$ as well as composite materials. ${ }^{7}$ They also have applications in molecular biology, owing to their properties, such as high surface area, low density, tunable surface functions, biocompatibility and biodegradability. ${ }^{9,10}$

CNWs can be produced from various lignocellulose sources by chemical and mechanical methods. The chemical methods used include acid hydrolysis, ${ }^{11}$ TEMPO oxidation, ${ }^{12}$ enzymatic hydrolysis ${ }^{13-15}$ etc., and while the CNFs or MFCs could be prepared through mechanical approaches, including refining, ${ }^{16}$ homogenizing, ${ }^{17}$ micro-fluidization, ${ }^{18-20}$ grinding, cryocrushing ${ }^{21-23}$ and high intensity ultra-sonication ${ }^{24-26}$ after various pulping processes, i.e. chemical, mechanical, and chemi-mechanical. These mechanical processes can be used separately or in combination. ${ }^{18,27}$ Comparing the properties of CNFs, in relation with the energy demand for their production by homogenization, microgrinding and micro-fluidization methods, Spence et $a l^{27}$ concluded that the highest specific surface area of CNFs was produced by homogenization. However, CNF films produced by micro-grinding and micro-fluidization showed superior physical, mechanical and optical properties, coupled with reduced energy consumption, in comparison with homogenization. Unfortunately, all the above mechanical procedures are energy-intensive and this can lead to a steep decline in both yields and fibril lengths. 
Thus, recent studies have shifted the focus to finding high-efficiency, environmentally friendly and low-cost methods to isolate CNWs.

Over the last few years, supercritical solvents have been proposed as a reaction system with the capability to enhance the effect of the pretreatment process. ${ }^{28}$ Supercritical fluids exhibit gas-like diffusivity and liquid-like dissolving capability, and this reduces the heat and mass transfer resistance during the reaction. However, two-state $\mathrm{CO}_{2}$ (gaseous and liquid) in the supercritical $\mathrm{CO}_{2}$ system has higher dissolution capability of polar and non-polar substances, and the liquid $\mathrm{CO}_{2}$ is acidic and has an autocatalytic effect on water removal from the amorphous region of cellulose. Subcritical water may also promote the hydrolysis of the amorphous and semi-crystalline regions of cellulose. This process shows great potential for cellulose nanocrystal production, because it uses only water as the hydrolyzing agent, and although it demands more energy due to the use of a high pressurized reactor, the overall process may be less expensive because it does not require numerous washing steps. However, more studies are needed exploring other reaction conditions in order to explain the mechanism of hydrolysis with subcritical water. A combination of pretreatment and refining processes has led to the successful fabrication of uniform CNWs with a high degree of fibrillation. ${ }^{29}$ Similarly, Wang and Cheng ${ }^{25}$ compared the application of high-intensity ultrasonication (HIUS) solely and in combination with high-pressure homogenization (HPH), and found that the combination of the two methods improved the effectiveness of fibrillation and produced uniform nanofibers, compared with one method used alone.

Herein, a new pretreatment process has been explored for the preparation of CNWs using supercritical carbon dioxide and ethanol. Supercritical carbon dioxide/ethanol pretreatment experiments were carried out on microfibrillated cellulose (MFC) using a laboratory autoclave, and the yields of pretreated MFC at different temperatures $\left(120,135,150,180\right.$ and $\left.200{ }^{\circ} \mathrm{C}\right)$ and times $(30,90,120,150$ and $180 \mathrm{~min})$ were examined. Cellulose nanofibers (CNFs) were also prepared using a Microfluidizer high pressure homogenizer. A comparative study was conducted on the properties of the raw materials, the CNWs and the CNFs using X-ray diffraction (XRD), scanning electron microscopy (SEM),
Fourier transform infrared spectrometry (FTIR) and thermogravimetric analysis (TGA).

\section{EXPERIMENTAL \\ Materials}

MFC (microfibrillated cellulose, average size: 250 $\mu \mathrm{m})$ and ethanol (99.8\%) were purchased from Aladdin Industrial Co., Hangzhou, China.

\section{Supercritical $\mathrm{CO}_{2} /$ ethanol pretreatment of $\mathrm{MFC}$}

A 100-mL SLP high-pressure autoclave (Century Senlong Experimental Apparatus Co. Ltd., Beijing, China) was used for the supercritical $\mathrm{CO}_{2}$ /ethanol pretreatment experiment on MFC. In a typical run, 2.5 $\mathrm{g}$ of MFC was placed in the reactor with $75 \mathrm{~mL}$ of ethanol solution $(4: 1, \mathrm{v} / \mathrm{v})$. The inside pressure was controlled by injecting carbon dioxide gas $(0,1.5$ and 3 Mpa). The reactor was then sealed and allowed to run at a pre-specified temperature of $90-200{ }^{\circ} \mathrm{C}$ and a reaction time of 30-180 min. The reactor was shockcooled with water to room temperature as the pretreatment reaction was completed. The polymerization products were then transferred to a beaker and the reactor was washed with anhydrous ethanol. The mixture of ethanol washing liquid and pretreatment products was filtered through a $0.2-\mu \mathrm{m}$ microporous filter under vacuum. The retentate (pretreated MFC sample, P-MFC) was vacuum-dried at $-30{ }^{\circ} \mathrm{C}$ for $24 \mathrm{~h}$ to obtain the pretreated MFC product.

\section{Methods for preparation of CNWs and CNFs}

Particle size was further reduced by introducing an additional mechanical process using the suspension, which was fully reacted with supercritical $\mathrm{CO}_{2}$ in the ball mill for six hours. There were static and rotating grindstones in the ball-milling equipment and the pulp slurry material passed through these small stones together with the suspension. The goal of fibrillation in the grinder was to ensure the breaking down of the hydrogen bonds and cell wall core structure by shear forces and to reduce the pulp to nano-scale fibers. ${ }^{30}$ The supercritical $\mathrm{CO}_{2}$ pretreatment was therefore combined with ball-milling. Mechanical fibrillation by both ball-milling and supercritical $\mathrm{CO}_{2}$ seemed to randomly dismantle the crystalline and amorphous regions of the cellulose. This fracture of cellulose crystals is thought to be a factor contributing to the dissociation of micro-fibrils and their bundles. ${ }^{31}$

The bleached pretreated wood pulp was inactivated at high temperature in a boiling water environment. A PFI pulping machine (TB7-FFV, Xianyang Tongda Ltd., Shandong, China) was used for pulping the pulp slurry. The experiments were carried out through the processing of mechanical treatment by the PFI pulping machine at $47000 \mathrm{rpm}$ for $35 \mathrm{~min}$ at $25{ }^{\circ} \mathrm{C}$, which increased the degree of bleaching by pulp beating to around $90^{\circ} \mathrm{SR}$. The pulp suspension was then diluted with tap water and the suspension was passed through a high-pressure homogenizer (Microfluidizer TM- 
LMZO, Microfluidics, Westwood, MA) at 25,000 psi with 20 cycles to produce CNFs.

\section{Characterization \\ Yield}

The solid yield of MFC pretreated at different temperature $(120,135,150,180$ and 200) and time (30, $90,120,150$ and $180 \mathrm{~min}$ ) was calculated by the following formula.

Yield $=\frac{G_{1}}{G_{0}} \times 100 \%$

where $G_{1}$ represents the sample after drying and $G_{0}$ the initial MFC (2.5 g). The yield of P-MFC was also used as a response to the experimental design.

\section{Scanning electron microscopy (SEM)}

Scanning electron microscopy (SEM) was used for the analysis of the surface morphology of the nanofibrillated cellulose. Images were captured at a magnification of $10000 \times$ by means of a benchtop scanning electron microscope (Ultra55, Carl Zeiss AG, Oberkochen, Germany). The test was operated in the high vacuum mode at an acceleration voltage of $15 \mathrm{kV}$. The samples were secured on a metal stub with carbon tape and coated with a thin layer of gold using an HR sputter coater (Agar Scientific, Stansted, UK), prior to examination in order to render the products electroconductive.

\section{$X R D$}

Dried neat CNW films were separately mounted onto a special holder through which a beam of X-rays passed centrally. Scattering radiation was identified in the $2 \theta$ range from $2^{\circ}$ to $40^{\circ}$ at a scanning rate of $4^{\circ}$ $\min ^{-1}$. The crystallinity index was evaluated from the XRD patterns using Equation (2):

$\mathrm{CI}=\frac{I_{200}-I_{a m}}{I_{200}} \times 100 \%$

in accordance with the Segal method, where $I_{200}$ is the intensity height of the crystalline (200) peak (at $2 \theta=$ $\left.22.5^{\circ}\right), \mathrm{I}_{\mathrm{am}}$ is the minimum intensity height between (200) and $(101)$ peaks (at $\left.2 \theta=16.3^{\circ}\right){ }^{19}$

\section{Fourier transform infrared spectrometry (FT-IR)}

After drying MFC and $\mathrm{P}-\mathrm{MFC}, \mathrm{KBr}(\mathrm{KBr}$ : sample - 1:100 mass ratio) was added to each, respectively, it was ground into powder by a mortar and then pressed into tablets. The chemical bonds of MFC and P-MFC were analyzed by FT-IR (Nicolet 5700, ThermoFisher Scientific, Waltham, MA). The measurement was done using the $\mathrm{KBr}$ method for functionality changes in the range $400-4000 \mathrm{~cm}^{-1}$ (scans $\left.=32\right)$.

\section{Thermogravimetric analysis}

$10 \mathrm{mg}$ of MFC, P-MFC, CNWs and CNFs were dried in the oven. The thermogravimetric analyzer used in this study was a Pyris Diamond DSC (Perkin Elmer, Waltham, MA). Analysis was conducted in a nitrogen atmosphere, with a nitrogen flow rate of $200 \mathrm{~mL} \mathrm{~min}^{-1}$.
A temperature range of $20-800{ }^{\circ} \mathrm{C}$ and a heating rate of $10{ }^{\circ} \mathrm{C} \min ^{-1}$ were used.

\section{RESULTS AND DISCUSSION Effect of carbon dioxide/ethanol pretreatment on the properties of MFC Yield analysis}

The pretreated yields of MFC varied with temperature $\left(120,135,150,180\right.$ and $\left.200{ }^{\circ} \mathrm{C}\right)$ and time $(30,90,120,150$ and $180 \mathrm{~min})$ and are presented in Figure 1. As shown in Figure 1 (a), when the pretreatment temperature is set at 135 ${ }^{\circ} \mathrm{C}$, from $30 \mathrm{~min}$ to $150 \mathrm{~min}$, the solid-phase yield of P-MFC decreases from $96.1 \%$ to $87.3 \%$, which decreases with the prolongation of pretreatment time. As shown in Figure 1 (b), when the pretreatment time is set at $90 \mathrm{~min}$, the solid-phase yield of P-MFC reaches the maximum at $135 \square$. Both increasing temperature and lowering temperature will reduce the yield of P-MFC.

When the reaction time was $30 \mathrm{~min}$ and the pretreatment temperature was $135 \square$, the solid yields of MFC, without supercritical $\mathrm{CO}_{2}$ pretreatment and with supercritical $\mathrm{CO}_{2}$ pretreatment, were $90.5 \%$ and $96.1 \%$, respectively. This indicates that the supercritical $\mathrm{CO}_{2}$ process may have a definite enhancement effect on the amorphous zone hydrolysis reactions of MFC. According to the above conclusions, the hydrolysis reaction in the amorphous region of MFC increases with the increase of pretreatment temperature and time. According to Lin and Dufresne, $^{32}$ the solid yield of P-MFC by the supercritical carbon dioxide/ethanol pretreatment process is higher than that of MFC after sulfuric acid pretreatment. It is obvious that the amorphous region of P-MFC is hydrolyzed to a large extent. The higher the yield, the more hydrolysis in the amorphous zone, which proves that sufficient temperature and time can ensure the hydrolysis. However, with the increase of time and temperature, too severe conditions lead to hydrolysis in the crystallization zone.

\section{SEM analysis}

SEM micrographs of MFC pretreated under different conditions are shown in Figure 2. The surface of MFC was smooth and single fibers were tightly bonded together. ${ }^{33}$ The morphology of P-MFC obtained from MFC pretreated at 135 ${ }^{\circ} \mathrm{C}$ for $30 \mathrm{~min}$ indicates that the bunch of fibers was divided into single fibers, but the length and diameter of P-MFC were basically maintained (see Fig. 2a). As the pretreatment time increased 
to $150 \mathrm{~min}$ (see Fig. 2c), the length and diameter of P-MFC clearly decreased, in contrast to the situation when the pretreatment temperature increased to $200{ }^{\circ} \mathrm{C}$ (see Fig. 2d). The trend in PMFC morphology suggests that the pretreatment time has a greater effect on the MFC size than the pretreatment temperature. The explanation may be that the hydrolysis rate of the reaction at 135

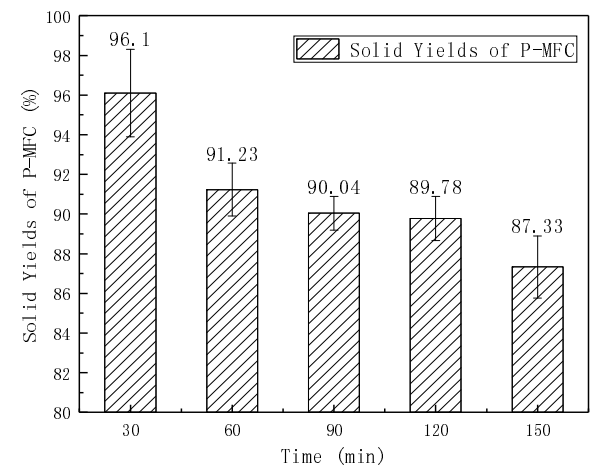

a)

Figure 1: Solid yields of P-MFC for different temperatures and reaction times
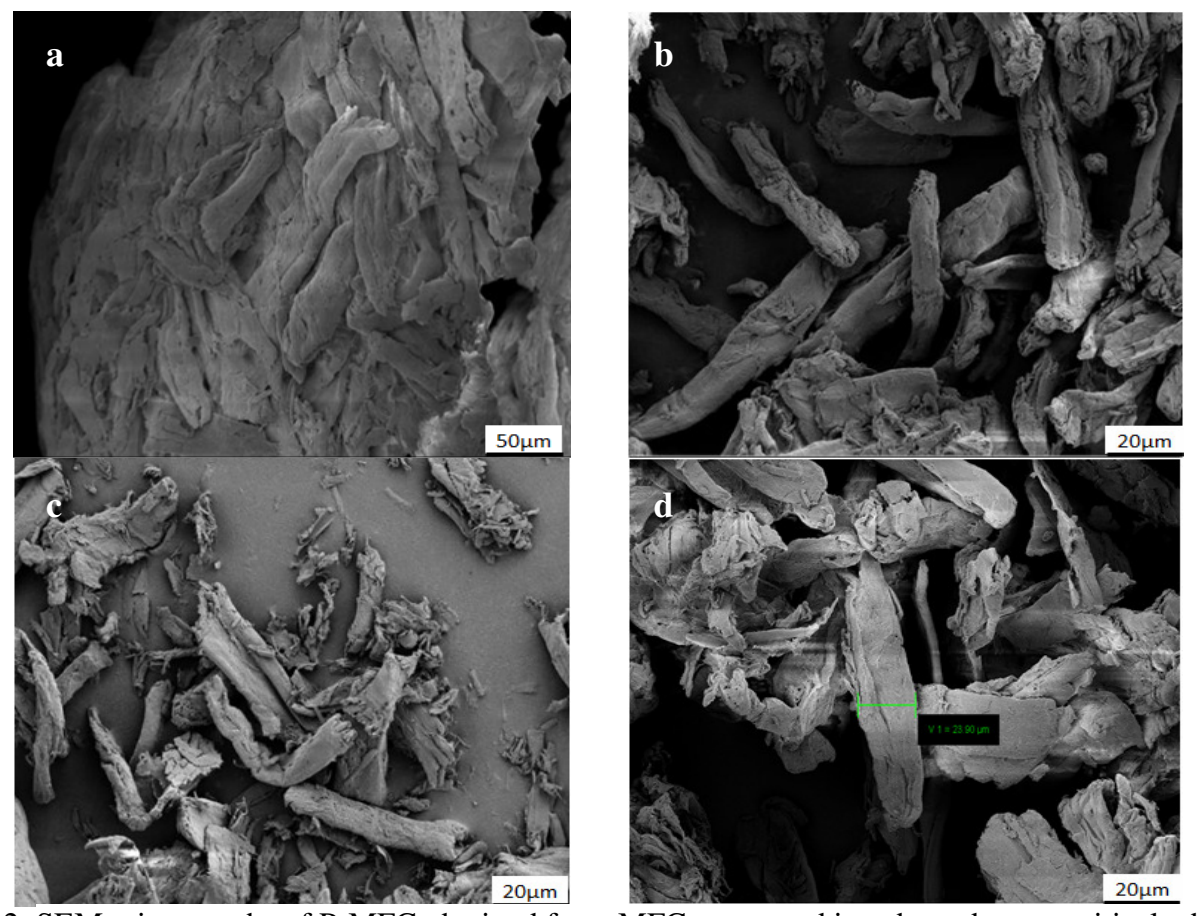

Figure 2: SEM micrographs of P-MFC obtained from MFC pretreated in sub- and super-critical ethanol;

(a) MFC; (b) $135{ }^{\circ} \mathrm{C}, 30 \mathrm{~min}, 1.5 \mathrm{Mpa}$; (c) $135^{\circ} \mathrm{C}, 150 \mathrm{~min}, 1.5 \mathrm{Mpa}$; (d) $200{ }^{\circ} \mathrm{C}, 30 \mathrm{~min}, 1.5 \mathrm{Mpa}$

\section{XRD analysis}

The XRD patterns of the original MFC material and the P-MFC obtained from MFC pretreatment at different reaction times and temperatures are shown in Figure 3 . The
${ }^{\circ} \mathrm{C}$ was similar to that at $200{ }^{\circ} \mathrm{C}$. A longer reaction time was required to reduce the $\mathrm{MFC}$ size by hydrolysis. The supercritical carbon dioxide/ethanol pretreatment can therefore decrease the length and diameter value of MFC under pretreatment conditions of $135^{\circ} \mathrm{C}$ for 150 $\min$.

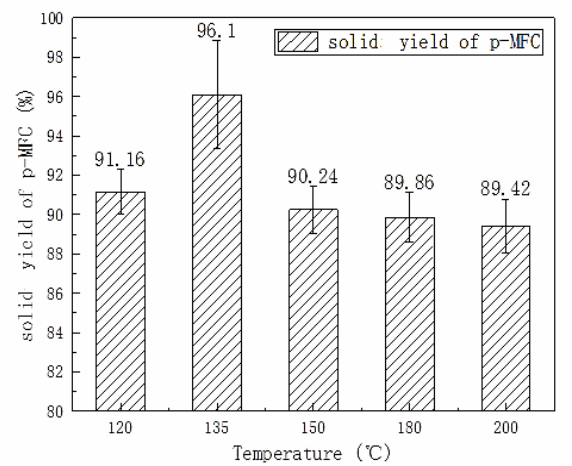

b) 
on the left of the graphs, suggesting that the fibers contained a substantial region of native cellulose I, as shown by the characteristic peak at $22.6^{\circ}$, which corresponds to the lattice plane of cellulose I. ${ }^{34}$ This indicates that the hydrolysis by supercritical $\mathrm{CO}_{2}$ did not change the crystalline structure of MFC, and this agrees with the results obtained in previous studies. ${ }^{29,35}$

The crystallinity index in Figure 3 shows that the XRD crystallinity for P-MFC pretreated with supercritical $\mathrm{CO}_{2}$ increased to $73.98 \%$, compared with MFC. The above hypothesis that the enzyme

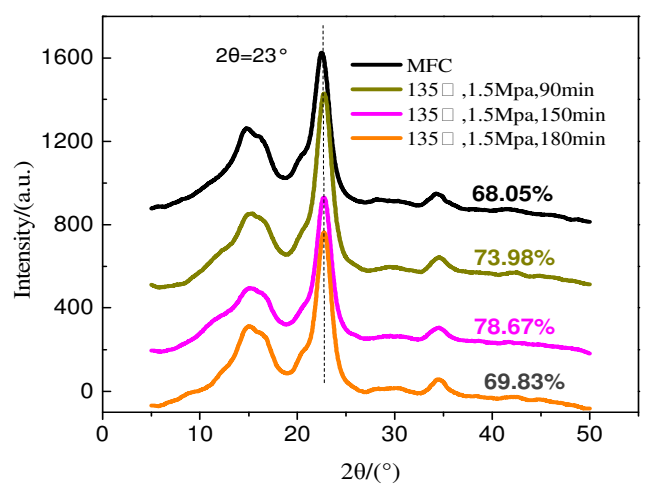

Figure 3: XRD analysis of P-MFC obtained from MFC pretreated at different reaction times and temperatures
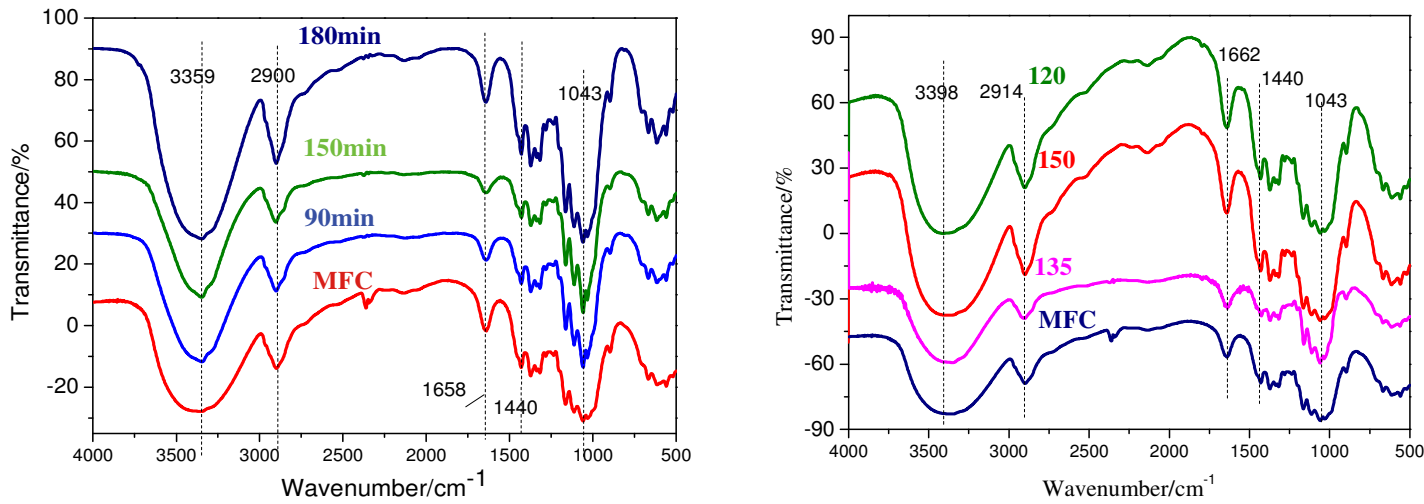

Figure 4: FT-IR analysis of P-MFC obtained from MFC pretreated at different reaction times and temperatures

The reaction temperature also exerted a substantial effect on the crystallinity of P-MFC. Figure 3 shows the XRD crystallinity of P-MFC pretreated with supercritical $\mathrm{CO}_{2}$ at different reaction temperatures. The trend of crystallinity was an initial increase, followed by a decline. The amorphous region of the microcrystalline cellulose hydrolyzed first and, with increasing time, the crystalline area also hydrolyzed. With supercritical $\mathrm{CO}_{2}$ pretreatment, the crystallinity index of MFC was $74.08 \%$ at $135{ }^{\circ} \mathrm{C}$, and this may be regarded as the optimum pretreatment temperature for MFC. picked partially digested amorphous regions is supported by the increase in crystallinity. The crystallinity index of P-MFC initially increased and then decreased as the reaction time increased, and this indicates that the amorphous region of MFC hydrolyzed first, and with increasing time, the crystalline area was also broken. A reaction time of 150 min may, therefore, be considered the optimum reaction time in this experiment due to the higher crystallinity index of P-MFC.

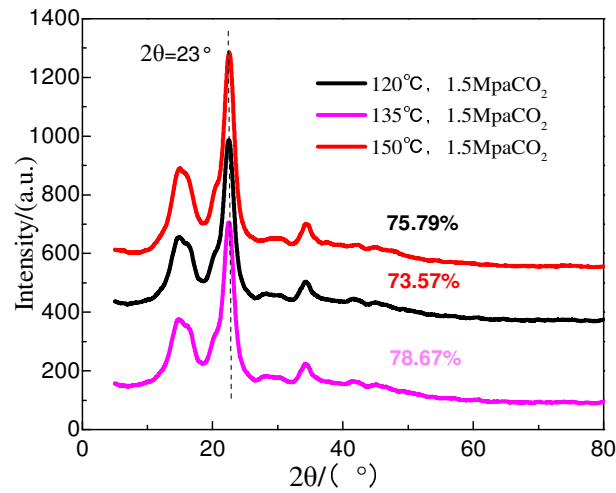


different peaks, a stronger characteristic peak indicates a higher functional group content. Additionally, a band at $2900 \mathrm{~cm}^{-1}$ was detected, showing $\mathrm{C}-\mathrm{H}$ stretching vibrations, which are due to $\mathrm{CH}_{2}$ and $\mathrm{CH}_{3}$ groups. The prominent band at $1043 \mathrm{~cm}^{-1}$ was attributed to $\mathrm{C}-\mathrm{O}$ and $\mathrm{C}-\mathrm{C}$ stretching and to the contribution of glycosidic linkages.

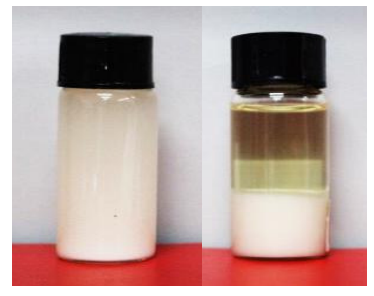

a) P-MFC

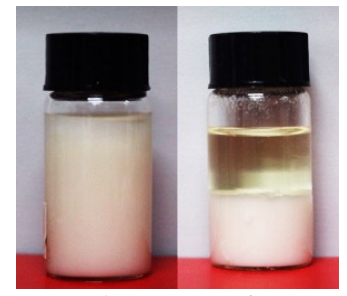

b) $\mathrm{CNWs}-6$

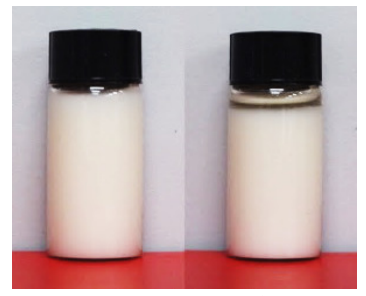

c) $\mathrm{CNWs}-24$

Figure 5: Visual appearance of suspensions of P-MFC and CNWs obtained from P-MFC ground for $6 \mathrm{~h}$

(CNWs-6) and $24 \mathrm{~h}$ (CNWs-24)

In Figure 4, the characteristic peaks at 2915 $\mathrm{cm}^{-1}$ correspond to $\mathrm{C}-\mathrm{H}$ stretching vibration, and this peak vibrates more strongly with increasing temperature. Similarly, the short band at $1662 \mathrm{~cm}$

${ }^{1}$ in all spectra originates from absorbed moisture. A series of constant short peaks occur in the range $1043-1440 \mathrm{~cm}^{-1}$, which are associated with the deformation of $\mathrm{C}-\mathrm{H}$ bonds on the glucoside keys. In general, the addition of P-MFC did not cause any reactions to generate any new chemical bonds, according to the FT-IR curves with 1440 $\mathrm{CH} 2$ bending vibration and $893 \mathrm{C}-\mathrm{O}-\mathrm{C}$ stretching vibration. This observation corroborates with our previous XRD results.

\section{Effect of carbon dioxide/ethanol pretreatment on the properties of CNWs \\ Analytical properties of CNW suspensions}

The $12 \mathrm{~h}$ suspension properties of P-MFC and CNWs generated by P-MFC grinding for $6 \mathrm{~h}$ and $24 \mathrm{~h}$ are shown in Figure 5. Compared to P-MFC, the CNWs at different fibrillations are semitransparent and well dispersed in water. This is owing to the strong hydrogen bonding between water and readily available hydroxyl groups resulting from the microfibril liberation. ${ }^{36}$ The suspension stability of CNWs-24 is greater than that of CNWs-6. Increasing ball-milling time enhanced the micro-fibrillation effect of the CNWs.

\section{SEM analysis of CNWs}

Comparing the group pictures, the supernatant liquid declined with increasing ball milling time when the suspension was allowed to rest for $12 \mathrm{~h}$. Thus, the suspension may have become more stable after a longer ball milling time. This indicates that the CNWs may have only a crystalline region after the applied pretreatment through supercritical carbon dioxide treatment and grinding.

To determine the size of the CNWs, a dilute suspension was examined using SEM and the images are displayed in Figure 6. The length of CNWs was about $200 \mathrm{~nm}$ and the fiber diameter was about $20 \mathrm{~nm}$. They bonded together and presented a three-dimensional nano-structured network, comprising randomly arranged nanofibrils. The network by hydrogen bonds was enabled by the many hydroxyl groups in CNWs. Compared to the MFC materials, the surface of the CNWs became rougher, and a trace of erosion by the supercritical $\mathrm{CO}_{2}$ can be clearly seen. The length and the diameter were almost the same, indicating that prolonging the reaction time beyond $150 \mathrm{~min}$ did not facilitate the characterization of the CNWs. Meanwhile, the morphology of CNW is basically acicular, while that of CNF is mainly soft fibrous. Therefore, $\mathrm{CNWs}$ with supercritical $\mathrm{CO}_{2}$ pretreatment have already had the amorphous region removed. The pretreatment has an important role in reducing particle size and increasing specific surface area, thereby enhancing thermal stability. The results indicate that this is a potent and environmentally friendly route for the preparation of CNWs.

After the reactions, the sample surface showed a less white color produced by higher temperatures. Prolonging the pretreatment time of the reaction clearly showed differences, as can be seen in the SEM micrographs (Fig. 6), with the diameter of the fibers shorter than before.

\section{Thermogravimetric analysis}

The thermal stability of MFC, P-MFC (135 $\left.{ }^{\circ} \mathrm{C}, 1.5 \mathrm{Mpa} \mathrm{CO}_{2}, 150 \mathrm{~min}\right)$, and CNWs $\left(135^{\circ} \mathrm{C}\right.$, 
1.5 Mpa $\mathrm{CO}_{2}, 150 \mathrm{~min}$, ball-milled for $6 \mathrm{~h}$ ) was determined by thermogravimetric analysis. Particles exhibited a loss in weight due to increasing temperature, and the rate of particle degradation is shown in Figure 7. An initial weight loss was observed in the MFC (about 350-

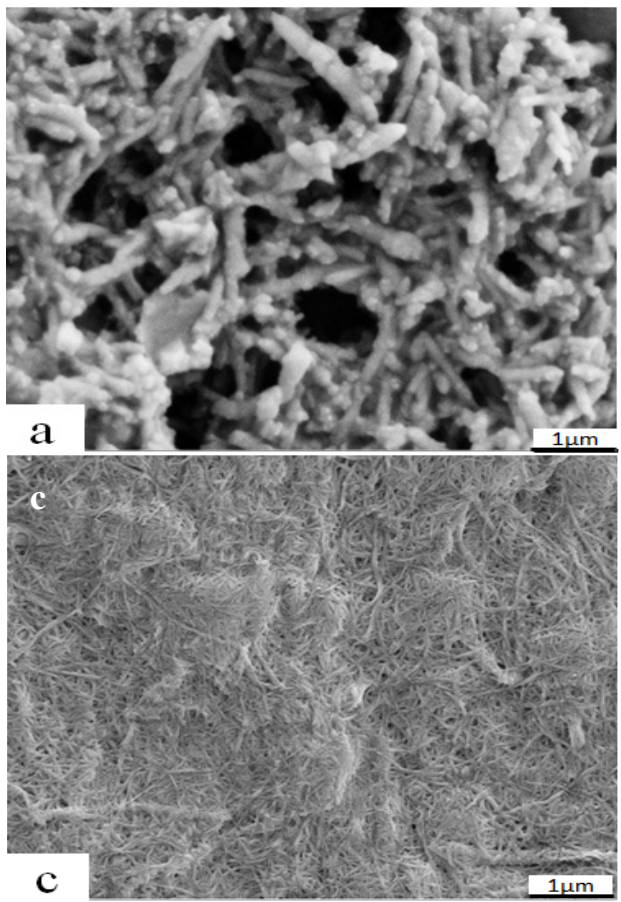

$\left.400{ }^{\circ} \mathrm{C}\right)$ and the CNWs $\left(135{ }^{\circ} \mathrm{C}, 1.5 \mathrm{Mpa} \mathrm{CO}_{2}\right.$, $150 \mathrm{~min}$ ) and is the result of the evaporation of water. With further increasing temperature $(\leq 800$ $\left.{ }^{\circ} \mathrm{C}\right)$, the TG curves of the MFC and P-MFC (135 ${ }^{\circ} \mathrm{C}, 1.5 \mathrm{Mpa} \mathrm{CO}_{2}, 150 \mathrm{~min}$ ) change in a similar fashion.

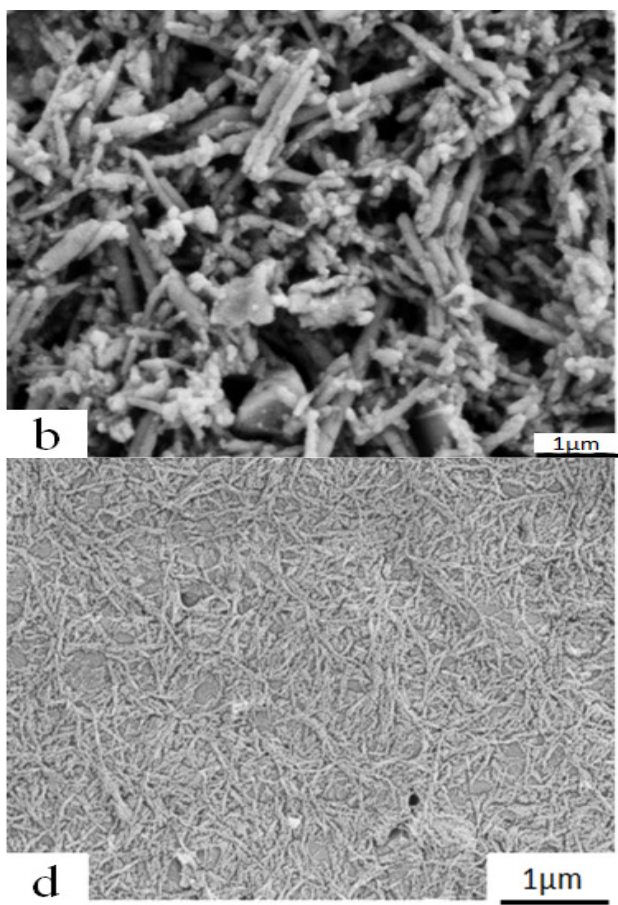

Figure 6: SEM images of CNWs at different reaction times; a), $135^{\circ} \mathrm{C}, 150 \mathrm{~min}, 1.5 \mathrm{Mpa}$ (twice), ground for $6 \mathrm{~h}$ (twice); b) $135^{\circ} \mathrm{C}, 180 \mathrm{~min}, 1.5 \mathrm{Mpa}$ (twice), ground for $6 \mathrm{~h}$ (twice); c) high-pressure homogenized 20 times; d) high-pressure homogenized 40 times

As regards the CNWs, their initial degradation temperature was about $250{ }^{\circ} \mathrm{C}$, which is lower than the degradation temperature of MFC. Also, the rate of weight loss of the CNWs $\left(135{ }^{\circ} \mathrm{C}, 1.5\right.$ $\mathrm{Mpa} \mathrm{CO}_{2}, 150 \mathrm{~min}$, ball-milled for $6 \mathrm{~h}$ ) was much lower than those of the CNF, MFC and P-MFC. These results may be explained by decreased polymerization and increased specific surface, and consequently the loss of active groups. However, the thermal stability of the CNWs produced by supercritical water hydrolysis was much higher than that of nanofibrillated cellulose produced by sulfuric acid hydrolysis, owing to the absence of sulfate groups in the CNWs produced by hydrolysis with supercritical $\mathrm{CO}_{2}{ }^{32}$ According to an earlier study, ${ }^{37}$ the weight loss of CNWs produced by supercritical carbon dioxide is much less than that of nanofibrillated cellulose produced by sulfuric acid. The TG curves did not show large changes $\left(\leq 800{ }^{\circ} \mathrm{C}\right)$ with increasing temperature, indicating higher thermal stability. Thus, the thermal stability of the CNWs is clearly higher than those of the $\mathrm{CNF}$ and the raw material. The increased thermal stability of cellulose fibrils (compared to MFC) might be attributed to strong hydrogen bonding between the hydroxyl groups of the cellulose fibrils. ${ }^{38}$ The higher thermal stability of the CNWs can be attributed to their flexibility and hence a greater possibility of entanglement of the nanofibrils. A comparable increase in thermal stability due to the tangling effect of flexible microfibrils has been reported by Das et al. ${ }^{39}$ The melting peaks of the crystalline CNWs were observed in the temperature range $230-250{ }^{\circ} \mathrm{C}$. However, this was not observed in the case of any MFC, because the removal of the amorphous portion by chemical treatments in CNWs increased the crystallinity of the CNWs. ${ }^{40}$ In most reactions, the temperature was an important factor, but the P-MFC yield was 
predominantly influenced by timing. Figure 7 indicates a low significance of the carbon dioxide factor. The thermal stability of cellulose whiskers is important, considering their potential application as a reinforcing filler in polymer composites, especially in thermoplastics, as processing temperatures often exceed $200{ }^{\circ} \mathrm{C}$. ${ }^{41}$
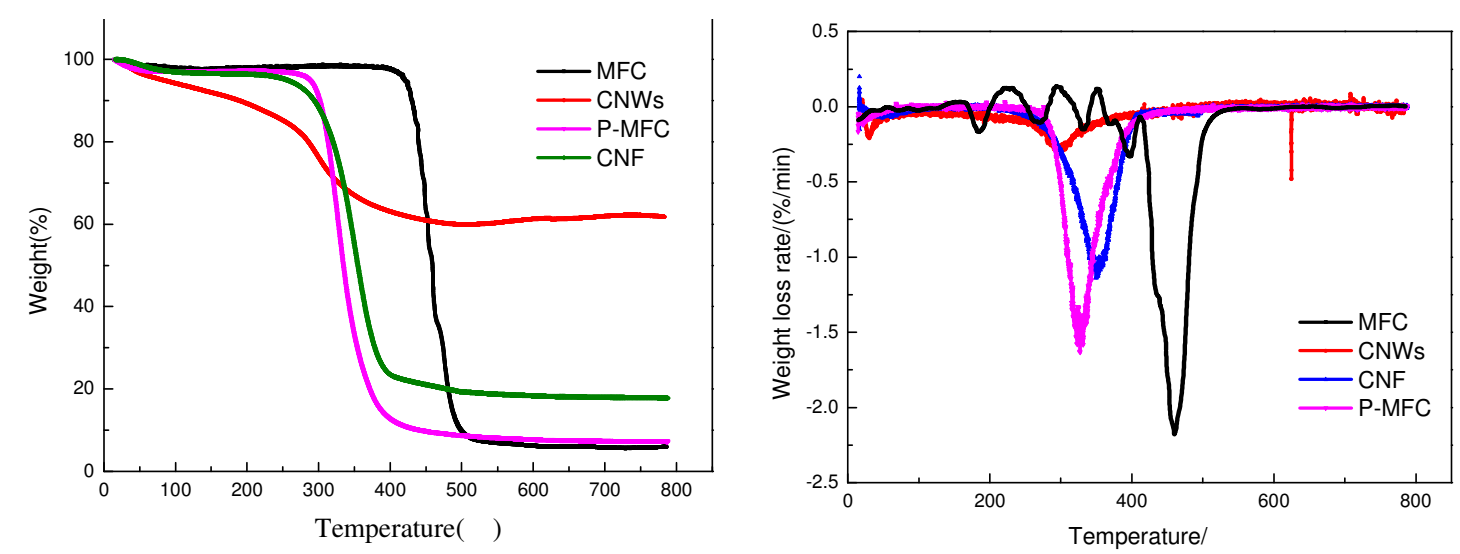

Figure 7: Thermogravimetric curves of MFC, P-MFC, CNWs and CNFs
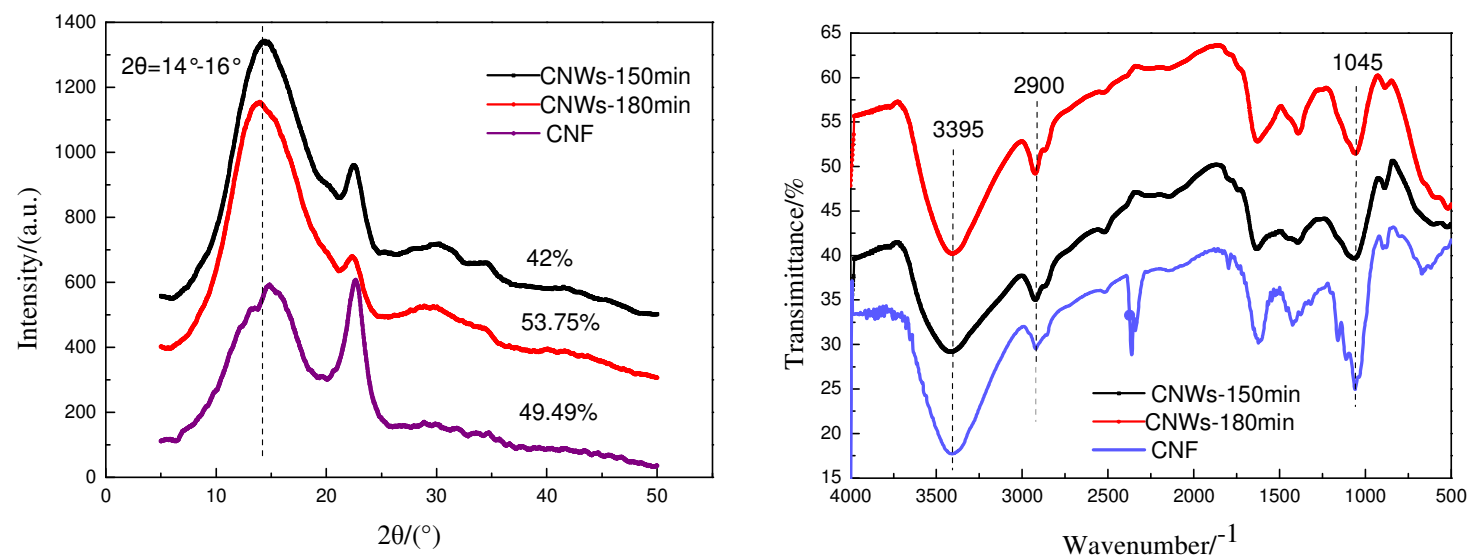

Figure 8: XRD and FT-IR of CNWs for different reaction times

\section{XRD and FTIR of CNWs during different reaction times}

Comparative XRD in Figures 3 and 8 show crystalline peaks at $2 \theta=14-16^{\circ}$, indicating an increase in the crystallinity of the CNWs; the crystallinity value of CNWs was larger than that of CNFs. It may be concluded that during acid hydrolysis, cellulose possessing a loose structure favors changes in the size of the crystallites. Tang et $a l^{42}$ suggested the explanation that changes in crystallite size during acid hydrolysis were the result of both the degradation of smaller crystallites and the growth of defective crystallites.
Figure 8 presents the characteristic peaks of CNWs produced during different reaction times. The broad absorption band at $3395 \mathrm{~cm}^{-1}$ is ascribed to hydroxyl groups that arise as a result of the association between the polymers. The characteristic peak was strong, thereby showing that the hydroxyl content was higher. Furthermore, a band at $2248 \mathrm{~cm}^{-1}$ was observed, indicative of $\mathrm{C}-\mathrm{H}$ stretching vibrations due to $\mathrm{CH}_{2}$ and $\mathrm{CH}_{3}$ groups. The prominent band at $1045 \mathrm{~cm}^{-}$ ${ }^{1}$ was assigned to $\mathrm{C}-\mathrm{O}$ and $\mathrm{C}-\mathrm{C}$ stretching and the glycosidic linkage contribution. A series of constant short peaks occurred from 1045 to 1465 $\mathrm{cm}^{-1}$, and were attributed to the deformation of C$\mathrm{H}$ on the glycoside keys. 
Figure 8 shows the influence of reaction time as a factor. Compared to Figure 5, there was little change. In general, this indicates that the ballmilling did not generate any new chemical bonds, according to the information on the FT-IR curves.

\section{CONCLUSION}

Herein, a novel pretreatment method using supercritical $\mathrm{CO}_{2}$ was proposed, which was found to be an effective and environmentally friendly reaction medium for cellulose, without using an organic solvent. SEM showed that the morphology of CNWs was basically acicular, while that of CNFs was mainly soft fibrous. Thermogravimetric analysis suggested that the thermal stability of CNWs was substantially higher than those of the CNFs and the raw material. XRD analysis also indicated that CNWs have higher crystallinity than MFC or CNFs.

ACKNOWLEDGEMENTS: This work was funded by Zhejiang Provincial Key Research and Development Project (No. 2019C01156), Zhejiang Provincial 26 County Green Special project (No. 2019C02042) and Zhejiang Provincial Public Welfare Technology Research Project (No. LGG19C160001), Zhejiang Philosophy and Social Science Project (No. 20NDJC144YB), the National Natural Science Foundation of China (No. 21808209), and Zhejiang Provincial Natural Science Foundation of China (No. LQ18C160003).

\section{REFERENCES}

A. Dufresne, "Nanocellulose: From Nature to High Performance Tailored Materials", De Gruyter, 2011, https://doi.org/10.1515/9783110254600

2 N. V. Ehman, A. F. Lourengo, B. H. McDonagh, M. E. Vallejos, F. E. Felissia et al., Int. J. Biol. Macromol., 143, 453

(2020), https://doi.org/10.1016/j.ijbiomac.2019.10.165

3 N. V. Ehman, Q. Tarrés, M. Delgado-Aguilar, M. E. Vallejos, F. Felissia et al., Cellulose Chem. Technol, 50, 361 (2016),

https://www.cellulosechemtechnol.ro/pdf/CCT34(2016)/p.361-367.pdf

4 C. J. Chirayil, L. Mathew and S. Thomas, Rev. Adv. Mater. Sci., $\quad 37, \quad 20 \quad$ (2014), https://doi.org/10.1007/s12598-014-0288-1

5 H. P. S. A. Khalil, A. H. Bhat and A. F. I. Yusra, Carbohyd. Polym., 87, $963 \quad$ (2012), https://doi.org/10.1016/j.carbpol.2011.08.078

6 J. D. Mendez and C. Weder, Polym. Chem.-UK, 1, 1237 (2010), https://doi.org/10.1039/COPY00118J

7 A. C. Leung, S. Hrapovic, E. Lam, Y. Liu, K. B. Male et al., Small, 7, 302 (2011), https://doi.org/10.1002/smll.201001715

8 A. P. Mangalam, J. Simonsen and A. S. Benight, Biomacromolecules, $10,497 \quad$ (2009), https://doi.org/10.1021/bm800925x

9 L. Brinchi, F. Cotana, E. Fortunati and J. M. Kenny, Carbohyd. Polym., 94, 154 (2013), https://doi.org/10.1016/j.carbpol.2013.01.033

10 N. Durán, A. P. Lemes, M. Durán, J. Freer and J. Baeza, J. Chil. Chem. Soc., 56, 672 (2011), https://doi.org/10.4067/S0717-97072011000200011

11 G. Ebe, F. Ham-Pichavant, E. Ibarboure, E. lbarboure, A. L. C. Koffi et al., Biomacromolecules, 13, 570 (2012), https://doi.org/10.1021/bm201777j

${ }^{12}$ H. Fan, N. Ji, M. Zhao, L. Xiong and Q. J. Sun, Food Chem., 192, $865 \quad$ (2016), https://doi.org/10.1016/j.foodchem.2015.07.093

13 J. H. Zhang, B. X. Zhang, J. Q. Zhang, L. Lu and L. Liu, Biotechnol. Adv., 28, 613 (2010), https://doi.org/10.1016/j.biotechadv.2010.05.010

14 S. R. Anderson, D. Esposito, W. Gillette, J. Y. Zhu and S. E. Mcneil, TAPPI J., 13, 35 (2014), https://doi.org/10.32964/TJ13.5.35

15 H. Kangas, F. Felissia, D. Filgueira, N. Ehman, M. E. Vallejos et al., Bioengineering, 6, 60 (2019), https://doi.org/10.3390/bioengineering6030060

16 W. Stelte and A. R. Sanadi, Ind. Eng. Chem. Res., 48, 11211 (2009), https://doi.org/10.1021/ie9011672

17 A. N. Nakagaito and H. Yano, Appl. Phys. A: Mater., $\quad 78, \quad 547 \quad$ (2004), https://doi.org/10.1007/s00339-003-2453-5

18 K. L. Spence, R. A. Venditti, Y. Habibi, O. J. Rojas, J. J. Pawlak et al., Bioresour. Technol., 101, 5961

(2010),

https://doi.org/10.1016/j.biortech.2010.02.104

19 J. Y. Zhu, R. Sabo and X. L. Luo, Green Chem., 13, 1339 (2011), https://doi.org/10.1039/c1 gc15103g

${ }^{20}$ T. Zimmermann, N. Bordeanu and E. Strub, Carbohyd. Polym., 79, $1086 \quad$ (2010), https://doi.org/10.1016/j.carbpol.2009.10.045

21 A. Alemdar and M. Sain, Bioresour. Technol., 99, 1664

(2008),

https://doi.org/10.1016/j.biortech.2007.04.029

22 A. Chakraborty, M. Sain and M. Kortschot, Holzforschung, $\quad \mathbf{9 8}, \quad 135 \quad$ (2005), https://doi.org/10.1515/HF.2005.016

23 W. Bei and M. Sain, Polym. Int., 56, 538 (2010), https://doi.org/10.1002/pi.2167

${ }^{24}$ W. Chen, H. Yu, Y. Liu, P. Chen, M. Zhang et al., Carbohyd. Polym., 83, $1804 \quad$ (2011), https://doi.org/10.1016/j.carbpol.2010.10.040

${ }_{25}$ Q. Cheng, S. Wang and T. G. Rials, Compos. Part A-Appl. Sci., 40, $218 \quad$ (2009), https://doi.org/10.1016/j.compositesa.2008.11.009

26 G. H. D. Tonoli, E. M. Teixeira, A. C. Corrêa, J. M. Marconcini, L. A. Caixeta et al., Carbohyd. Polym., 89, 80

(2012),

https://doi.org/10.1016/j.carbpol.2012.02.052

27 K. L. Spence, R. A. Venditti, O. J. Rojas, Y. Habibi and J. J. Pawlak, Cellulose, 18, 1097 (2011), 
https://doi.org/10.1007/s10570-011-9533-z

28 Y. J. Lu and Y. G. Zu, Food Ind., 40, 100 (2019), https://kns.cnki.net/kcms/detail/detail.aspx?dbcode $=$ CJ FD\&dbname $=$ CJFDLAST2019\&filename $=$ SPGY2019 02024\&v=Ge2mjeLCggcQjg510\%25mmd2Fo9GuH\% 25mmd2B6QSXKE9KvrmEy\%25mmd2FjmExsFgCk yH5I7F3EcHEf3AfWI

${ }_{29}$ Y. Qing, R. Sabo, J. Y. Zhu, U. Agarwal, Z. Cai et al., Carbohyd. Polym., 97, 226 (2013), https://doi.org/ 10.1016/j.carbpol.2013.04.086

30 I. Siró, D. Plackett, I. Siro and D. Plackett, Cellulose, 17, 459 (2010), https://doi.org/10.1007/s10570-010-9405-y

31 X. Wang, Y. Zhang, H. Jiang, Y. Song, Z. Zhou et al., Mater. Lett., 183, $179 \quad$ (2016), https://doi.org/10.1016/j.matlet.2016.07.081

32 N. Lin and A. Dufresne, Nanoscale, 6, 5384 (2014), https://doi.org/10.1039/c3nr06761k

33 J. Zhang, H. Song, L. Lu, J. Zhuang, C. Pang et al., Biomass Bioeng., 39, $78 \quad$ (2012), https://doi.org/10.1016/j.biombioe.2010.06.013

34 I. Besbes, S. Alila and S. Boufi, Carbohyd. Polym., 84, 975 (2011), https://doi.org/10.1016/j.carbpol.2010.12.052

35 T. Saito, M. Hirota, N. Tamura, S. Kimura, H. Fukuzumi et al., Biomacromolecules, 10, 1992 (2009), https://doi.org/ 10.1021/bm900414t

36 M. Pääkkö, M. Ankerfors, H. Kosonen, A. Nykänen and S. Ahola, Biomacromolecules, 8, 1934 (2007), https://doi.org/ 10.1021/bm061215p

37 H. D. Jeong, C. R. Yoon, J. H. Lee and D. S. Bang, Elastomers and Composites, 45, 51 (2010), https://www.koreascience.or.kr/article/JAKO20101945 1499227.page

38 G. G. Chen, X. M. Qi, M. P. Li, G. Ying, B. Jing et al., Sci. Rep.-UK, 5, $16405 \quad$ (2015), https://doi.org/10.1038/srep16405

39 K. Das, D. Ray, N. R. Bandyopadhyay and S. Sengupta, J. Polym. Environ., 18, 355 (2010), https://doi.org/10.1007/s10924-010-0167-2

40 K. Das, D. Ray, N. R. Bandyopadhyay, T. Ghosh, A. K. Mohanty et al., Cellulose, 16, 783 (2009), https://doi.org/10.1007/s10570-009-9280-6

${ }_{41}$ W. Gindl and G. Jeronimidis, J. Mater. Sci., 39, 3245

(2004), https://doi.org/10.1023/B:JMSC.0000025870.09117.f6 ${ }_{42}$ L. G. Tang, N. S. Hon, S. H. Pan, Y. Q. Zhu, Z. Wang et al., J. Appl. Polym. Sci., 59, 483 (1996), https://doi.org/10.1002/(SICI)10974628(19960118)59:33.0.CO;2-V 